\title{
TRABALHO E INFÂNCIA: O OUTRO LADO DA MOEDA
}

\author{
Laís Leni Lima ${ }^{1}$ \\ Mariana Lima Martins ${ }^{2}$
}

\begin{abstract}
RESUMO: A relação trabalho e educação não é simples de ser estabelecida em função da configuração que o trabalho adquiriu na sociedade contemporânea. Essa relação torna-se mais difícil se acrescentarmos a ela a infância. Reduzidos ao mundo do capital, educação, trabalho e infância perdem seus princípios fundamentais. O processo de trabalho, quando reproduzido na esfera da dominação e da alienação, gera e alimenta um desequilíbrio formativo no mundo da infância. O objetivo deste artigo é compreender a seguinte problematização: por que a sociedade do capital condena o trabalho para a criança ao mesmo tempo em que estimula o consumismo? No decorrer da discussão teórica, propomos pensar os conceitos - trabalho, educação, infância. As fontes pesquisadas contemplaram Marx (1996, 2002), Mascarenhas (2012), Lima (2005, 2010), Arce (2004, 2007), Kuhlmann Junior (1991, 1998a), Stearns (2006), Heywood (2004), Kramer (2001), dentre outros. Apresentamos as análises de dados elaborados a partir de um estudo bibliográfico e empírico.
\end{abstract}

Palavras-chave: Trabalho. Educação. Infância.

\section{WORK AND CHILDHOOD: THE OTHER SIDE OF THE COIN}

ABSTRACT: The relation between work and education is not simple to be established in function of the configuration that the work acquired in the contemporary society. This relationship becomes more difficult if we add childhood in it. Reduced to the world of capital, education, work and childhood lose their fundamental principles. The process of work, when reproduced in the sphere of domination and alienation, generates and feeds a formative imbalance in the world of childhood. The purpose of this article is to understand the following problematization: why does the capital society condemn work for child while stimulating consumerism? During the theoretical discussion, we propose to think the concepts - work, education, childhood. The researched sources contemplated Marx (1996, 2002), Mascarenhas (2012), Lima (2005, 2010), Arce (2004, 2007), KuhImann Junior (1991, 1998a), Stearns (2006), Heywood Kramer (2001), among others. We present the data analyzes elaborated from a bibliographical and empirical study.

Keywords: Work. Education. Childhood.

\footnotetext{
${ }^{1}$ Doutora em Educação. Docente da Universidade Federal de Goiás (UFG). Goiânia-GO/Brasil. E-mail: laisleni@gmail.com

2 Mestranda no Programa de Pós-Graduação em Educação da Universidade Federal de Goiás (UFG). Goiânia-GO/Brasil.

E-mail: mary.lima706@gmail.com
}

Argumentos Pró-Educação, Pouso Alegre, v. 4, n. 12, p. 1118-1138, set. -dez., 2019

ISSN: 2448-2803 http://dx.doi.org/10.24280/ape.v4i12.519 


\section{TRABAJO E INFANCIA: LA OTRA CARA DE LA MONEDA}

RESUMEN: La relación entre trabajo y educación no es fácil de ser establecida según la configuración que adquiere el trabajo en la sociedad contemporánea. Esa relación se hace más difícil si añadimos a ella la infancia. Reducidos al mundo del capital, la educación, el trabajo y la infancia perdieron sus principios fundamentales. El proceso de trabajo, cuando se reproduce en la esfera de la dominación y la alienación, genera y nutre un desequilibrio formativo en el mundo de la infancia. El propósito de este artículo es entender el siguiente cuestionamiento: ¿por qué la sociedad del capital condena el trabajo a los niños, al mismo tiempo que estimula el consumismo? En el curso de la discusión, proponemos pensar los conceptos - trabajo, educación, infancia. Las fuentes estudiadas contemplaron Marx (1996, 2002), Mascarenhas (2012), Lima (2005, 2010), Arce (2004, 2007), Kuhlmann Junior (1991, 1998a), Stearns (2006), Heywood (2004), Kramer (2001), entre otros. Presentamos el análisis de los datos elaborados a partir de un estudio bibliográfico y empírico.

Palabras clave: Trabajo. Educación. Infancia.

Este texto tem como objeto de estudo compreender os conceitos trabalho, educação e infância para depois respondermos a seguinte problematização: em que medida a sociedade do capital condena o trabalho para a criança e ao mesmo tempo incentiva o consumismo? No primeiro momento, apresentamos a categoria trabalho por meio da concepção marxiana; no segundo, procuramos relacionar trabalho e educação e, por fim, buscamos compreender as concepções de infância constituídas socialmente. Nas considerações, trouxemos as análises dos dados levantados em uma pesquisa empírica de Trabalho de Conclusão de Curso (TCC), fazendo a reflexão com a problematização outrora anunciada.

Para alcançarmos a essência do nosso objeto de estudo ou a possibilidade de descobrir a essência dele, precisamos ir além da realidade que se apresenta em sua imediaticidade. Para tal, optamos pelo Materialismo Histórico-Dialético, que se apresenta como o método que melhor atende ao nosso objetivo. Essa abordagem surge para superar a separação entre o sujeito e objeto e compreender como o homem se relaciona com a natureza - entendendo por meio desta, a possibilidade de apreensão do objeto em sua natureza específica.

É um método que implica compreensão e transformação da realidade. Marx (1996; 2002), ao descobrir o segredo da mercadoria, ou seja, a lógica econômica objetiva da sociedade capitalista, fez a crítica ao seu fetichismo. Dessa forma, fez-se necessário partir das 
teorias marxianas para, primeiramente, entendermos a concepção de trabalho em Marx e, posteriormente, analisarmos a relação trabalho e educação, para então compreendermos os desdobramentos das relações fetichizadas que se desenvolvem no conceito de infância e, por fim, entendermos o porquê se condena o trabalho na infância. Para isso, foi necessário investigar os segredos que levam ao fetiche da mercadoria.

Entendemos que o objeto investigado está em constante mutação. Assim, nossa reflexão não se esgota, não está pronta, acabada; o que se propõe é uma abordagem, um diálogo inicial sobre as três realidades de estudo, a saber: a educação, o trabalho e a infância. Na perspectiva da abordagem do materialismo histórico-dialético, abordaremos os processos da natureza e da sociedade em sua conexão, reciprocidade e transformação. Segundo Triviños (2015, p. 51), "o materialismo histórico é a ciência filosófica do marxismo que estuda as leis sociológicas que caracterizam a vida da sociedade, de sua evolução histórica e da prática social dos homens, no desenvolvimento da humanidade".

A pesquisa em questão traz como principais referenciais teóricos os estudos de Marx (1996, 2002), Lima (2005; 2010), Arce (2004, 2007), Mascarenhas (2012), dentre outros. Após ter caracterizado o problema, elaborado os objetivos e definido o quadro teórico, os procedimentos e as técnicas foram delineados e seguidos na pesquisa.

Este estudo, uma vez bibliográfico, desenvolveu-se a partir de materiais já elaborados. Foi desenvolvida uma pesquisa de caráter qualitativo com enfoque dialético, objetivando investigar a relação entre trabalho, educação e infância. Ela tem característica explicativa, pois, de acordo com Gil (2010), tem como propósito explicar porque certos fatos contribuem para a ocorrência de fenômenos, ou seja, daquilo que se manifesta na realidade. No presente caso, estritamente, dos acontecimentos que se manifestam no campo da educação, no âmbito do trabalho e na realidade existencial da infância.

Para o procedimento desta pesquisa foram utilizadas entrevistas semiestruturadas e questionário com perguntas fechadas, em que os/as alunos/as graduandos/as do curso de Pedagogia da Universidade Federal de Goiás (UFG), Regional Jataí, dos períodos 5o e 7으, formaram o público-alvo/ou sujeitos. Entre esses sujeitos se encontraram alunos/as do turno matutino e noturno, totalizando 61 respondentes. A escolha do público-alvo (os graduandos/as do 5 e 70 períodos em Pedagogia) justifica-se pelo fato de estarem no 
penúltimo e último períodos do curso, e, portanto, esperava-se deles uma compreensão maior do sentido do trabalho, da educação e da infância.

O questionário trouxe 10 perguntas, três fechadas indicando o sexo, a existência e a quantidade de filhos - tendo em vista a importância destes critérios socioeconômicos para se entender o perfil de cada entrevistado, visto que para essa análise, o sexo e o vínculo à maternidade e paternidade podem influenciar suas concepções - e as demais em seu formato semiestruturado, destacando "qual a concepção os entrevistados apresentam a respeito de criança, infância, trabalho e educação". Também indagamos "se quando crianças foram submetidas a algum tipo de trabalho" e "qual a opinião acerca do trabalho para crianças, justificando se são a favor ou contra" - tendo em vista que a formação de concepções do homem é demarcada pelo processo histórico no qual são vivenciadas - e, finalmente, questionamos, "como consideram o papel educativo das gerações mais velhas acerca das mais novas". Certamente, essas variáveis trazem um impacto na constituição, conceitos pessoais, profissionais, políticos dos sujeitos pesquisados e, consequentemente, nas concepções de trabalho, criança, infância, levando em consideração o fato de as acadêmicas terem filhos e, portanto, de viverem o papel triplo de mãe, estudante e trabalhadora.

Segundo as análises de base marxiana de trabalho, o educador tem contribuído para a continuação de um trabalho sob a lógica do capital. Contudo, deveria ocorrer de forma contrária, cujo objetivo seria contribuir para a elevação da classe trabalhadora, assegurando conteúdos adequados e necessários à humanização e métodos adequados à apropriação da humanidade social e historicamente construída.

Bem sabemos que a educação não é, senão, uma, dentre outras possibilidades, que transforma o homem em humano; é marco de formação, de cuidado, de trato, de cultura, portanto, ela é decisiva na vida existencial do homem. De acordo com Saviani (2015), faz-se necessária a universalização de uma escola unitária que desenvolva, ao máximo, as potencialidades dos indivíduos, ou seja, a formação onilateral ${ }^{3}$, conduzindo-os ao desabrochar pleno de suas faculdades espirituais-intelectuais, buscando deixar o terreno da utopia e da

\footnotetext{
3 De acordo com Manacorda (2007), a constituição da onilateralidade se coloca em oposição à unilateralidade existente na sociedade atual. É o desenvolvimento total, completo, multilateral, em todos os sentidos, das faculdades e das forças produtivas, das necessidades e da capacidade da sua satisfação.
} 
mera aspiração ideológica, moral ou romântica, para converter-se numa exigência posta pelo próprio desenvolvimento do processo produtivo.

\section{Conceito marxiano de trabalho}

O homem constitui-se como tal por meio do trabalho. Esse, por sua vez, não é outra coisa senão uma atividade especificamente humana pela qual o objetivo que é antecipado mentalmente se realiza na prática. Para Marx (2002), trabalho é um processo que se dá entre o homem e a natureza. Por meio de sua própria ação regula, media, transforma-a. O trabalho é uma condição de existência do homem, a necessidade natural de mediação do metabolismo entre homem e natureza e, portanto, vida humana, como descreve Marx (2002):

O processo de trabalho, que descrevemos em seus elementos simples e abstratos, é atividade dirigida com o fim de criar valores-de-uso, de apropriar os elementos naturais às necessidades humanas; é condição natural eterna da vida humana, sem depender, portanto, de qualquer forma dessa vida, sendo antes comum a todas as suas formas sociais (MARX, 2002, p. 218).

É considerável, a partir da afirmação, situar a condição do trabalho enquanto fundamental para o ser humano, pois este é o que qualifica a existência do social. Com efeito, como uma atividade básica da produção e reprodução, na qual o homem faz a sua história. É uma atividade que cria e recria valores, em suma, é uma realidade natural e espontânea da vida dos homens; ao mesmo tempo, pode ser entendida como uma atividade criadora. Sem dúvida, é o que nos difere dos demais animais, é a expressão da práxis transformadora, constitui-se como fonte de realização e humanização, conforme ressalta Mascarenhas (2002) ao referir-se sobre o processo de humanização em Marx:

Humanizar-se é desenvolver-se dentro de um contexto de totalidade, de um desenvolvimento total, completo, multilateral, em todos os sentidos das faculdades e das forças produtivas, das necessidades e da capacidade da sua satisfação. É a construção do homem onilateral (MASCARENHAS, 2002, p. 51).

Nesse sentido, Marx (2002) define a importância do trabalho e o coloca como centro da humanização do homem. Na esteira de Marx, Martins (2004) corrobora com essa reflexão afirmando que o homem é parte da natureza e sobrevive somente por seu constante metabolismo com ela, tornando o trabalho uma atividade vital e o homem um ser natural ativo. Logo, é por essa atividade vital humana que o homem garante sua própria existência e 
de toda sociedade.

Nessa linha de pensamento, Marx (1996) entende que o trabalho é uma condição da atividade humana única, o que de fato diferencia o homem dos animais, e, ainda, que a primeira ação do homem na história foi a criação dos instrumentos para satisfazer as necessidades da produção de vida material, visto que,

sem dúvida, o animal também produz. Faz o ninho, uma habitação, como as abelhas, os castores, as formigas etc. Mas só produz o que é estritamente necessário para si e para outras crias; produz apenas numa só direção, ao passo que o homem produz universalmente; produz unicamente sobre a dominação da necessidade física imediata, enquanto o homem produz quando se encontra livre da necessidade física e só produz verdadeiramente na liberdade de tal necessidade; o animal apenas se produz a si, ao passo que o homem produz toda natureza; o seu produto pertence imediatamente seu corpo físico, enquanto o homem é livre perante seu produto. $O$ animal constrói apenas segundo o padrão de cada espécie a que pertence, ao passo que o homem sabe como produzir de acordo com o padrão de cada espécie e sabe como aplicar o padrão apropriado ao objeto; desse modo, o homem constrói também em conformidade com as leis da beleza (MARX, 1996, p. 165).

Considera, pois, o trabalho como uma troca com a natureza de forma consciente, intencionada e planejada. Desse modo, Marx (1996), ao comparar o trabalho com o desenvolvimento entre homem e natureza, elabora a concepção de que esse processo é uma atividade exclusiva do homem.

[...] pressupomos o trabalho numa forma em que pertence exclusivamente ao homem. Uma aranha executa operações semelhantes às do tecelão, e a abelha envergonha mais de um arquiteto humano com sua construção dos favos de suas colmeias. Mas o que distingue de antemão, o pior arquiteto da melhor abelha é que ele constitui o favo em sua cabeça, antes de construí-lo em cera. No fim do processo de trabalho obtém-se um resultado que já no início deste existiu na imaginação do trabalhador, e, portanto, idealmente. Ele não apenas efetua uma transformação da forma da matéria natural; realiza, ao mesmo tempo, na matéria natural seu objetivo, que ele sabe que determina, como lei a espécie e o modo de sua atividade e ao qual tem de subordinar sua vontade. E essa subordinação não é um ato isolado (MARX, 1996, p. 297-298).

Dessa forma, mesmo que a atividade humana seja inferior comparada à atividade dos animais, o trabalho humano é superior, pois de acordo com Lima (2010) é considerado como elemento da consciência. Entende-se então que, somente na relação com a natureza e com outros homens por meio do trabalho, o homem encontra a si mesmo como indivíduo, percebe-se como tal, assim como descreve Mascarenhas (2002, p. 50): “[...] o homem é um 
animal que só pode individualizar-se na sociedade"; isso implica identificar-se, valorizar e ao mesmo tempo estabelecer relações com o mundo, com a sociedade, com outros homens. E esse processo de socialização, em sua concepção original, é o processo educativo.

\section{Relação trabalho e educação}

O conceito de trabalho descrito nesse texto o concebe em seu potencial emancipador e humanizador. O trabalho é a forma pela qual o homem produz suas condições de existência, sua história, o próprio humano, situação que nos faz relacionar tal conceito com a educação. Nesse aspecto, concebemos a educação como um fenômeno próprio dos seres humanos. Saviani (2003) afirma que, para compreender a natureza da educação é preciso compreender a natureza humana. Conforme já mencionamos, o que diferencia os homens dos animais é que os primeiros transformam a natureza ao invés de adaptar-se a ela, e isto é feito pelo trabalho. Destarte, é de fundamental importância compreendermos que a educação, por sua vez, também não se encontra reduzida à execução de algo, mas como uma atividade humana e histórica, como uma prática social podendo definir o conjunto das relações sociais.

Nessa perspectiva, Frigotto (2000) entende que a educação pode ser entendida como o conjunto de conhecimentos, habilidades, atitudes e valores produzidos pelas classes sociais, para o desenvolvimento das potencialidades e a apropriação dos saberes adquiridos em uma determinada situação social, histórica e cultural. Aqui podemos encontrar a primeira relação entre trabalho e educação. Estão intrinsecamente ligados a partir da compreensão do trabalho como elemento fundamental da sociabilidade humana e, neste caso, a educação como instrumento essencial de socialização.

Marx, mesmo não elaborando uma teoria sobre educação escolar, nem se dedicando a esse tema, de certa forma, deixou reflexões que estabelecem uma prática educacional transformadora, ou seja, uma prática educativa em sentido amplo. Como bem sabemos, nessa época, a escola não tinha a proeminência que tem nos dias atuais. Em suas obras, em diferentes momentos, delineiam-se as bases filosóficas de uma concepção onilateral de educação e de qualificação humana, na perspectiva da instauração de novas relações sociais em uma nova sociedade. Essa teoria sobre educação é um processo, que está inserido numa sociedade na qual predomina a luta de classes, e que por meio desta é possível uma mudança 
de consciência, que permite ao homem modificar as circunstâncias; assim como afirma ser necessário estabelecer uma prática revolucionária.

De acordo com Saviani (2015), o avanço do capitalismo provoca na educação seus impactos, passando esta a ser entendida como algo decisivo para o desenvolvimento econômico e funcional ao sistema capitalista, não apenas ideologicamente, mas também economicamente, enquanto qualificadora da mão de obra (força de trabalho). O saber passa a ser força produtiva e propriedade privada das forças do poder, da ciência, da mídia, sobretudo, de alguns poucos poderosos. Assim, o saber não pode ser generalizado e apropriado por todos, do contrário, os trabalhadores passariam a ser proprietários dos meios de produção e a essência desta sociedade é que estes só detenham a força de produção necessitando, apenas, do saber mínimo para operar a produção. Ao capital não interessa a socialização das melhores produções humanas nos campos científico, artístico e filosófico a todos os indivíduos, pois isto seria uma ameaça a si próprio. Nessa mesma direção, Mészáros (2005) questiona: para que serve o sistema educacional, se não para lutar contra a alienação? Como descreve:

\begin{abstract}
A educação, que poderia ser uma alavanca essencial para a mudança, tornouse instrumento daqueles estigmas da sociedade capitalista: "fornecer os conhecimentos e o pessoal necessário à maquinaria produtiva em expansão do sistema capitalista, mas também gerar e transmitir um quadro de valores que legitima os interesses dominantes". Em outras palavras, tornou-se uma peça do processo de acumulação de capital e de estabelecimento de um consenso que torna possível a reprodução do injusto sistema de classes. Em lugar de instrumento da emancipação humana, agora é mecanismo de perpetuação e reprodução desse sistema (MÉSZÀROS, 2005, p. 15; grifo do autor).
\end{abstract}

Entretanto, aquela educação viva e borbulhante que o autor descreve, sem dúvida, tornou-se instrumento do capital, portanto, é limitada e reduz seu sentido amplo. Portanto, ela deixa de ser um processo que transforma o homem em humano, mais que isto, empobrece o sentido qualitativo do social. Assim, mesmo não se tratando de uma mercadoria, a educação tem se transformado em lógica de obtenção de lucro.

É nesse sentido que precisamos pensar outro modelo de educação, de escola, logo, de outra formação, de outro trabalhador. O trabalho educativo, como formação humana, como produção da existência de humanidade não pode ser alienado. Tendo em vista os estudos de Mészáros (2005), o trabalho educativo deve considerar a sociedade, tendo como referência o 
ser humano. Exige-se, assim, a superação da lógica desumanizadora do capital que tem sido o consumismo, o individualismo, o lucro, a competição, o poder, o mercado, a economia, a mídia, os grandes empresários e banqueiros.

A finalidade da educação, para esse autor, é transformar o trabalhador e sua própria existência. De certo modo, podemos expressar também, que a meta educativa é transformar o trabalhador em um agente político, mais que isto, um político pensante, ao mesmo tempo, que saiba falar e agir. Metaforicamente, a educação seria uma arma para transformar o mundo do homem e seu trabalho. Portanto, deve ela ser objeto de transformação radical e de contestação desse modelo de sociedade; do econômico, do político, do hegemônico e, esta transformação se dá por diferentes mediações que se relacionam de modo objetivo e subjetivo no trabalho.

Esse processo de produção material e educação, sob qual o modo capitalista organiza a reprodução econômica e social, repercute um impacto negativo a respeito da classe trabalhadora, pois de acordo com Mészáros (2005), esse sistema limita a mente e a ação humana, tornando-as incapazes de elevar o homem à transcendência positiva da auto alienação do trabalho; consequentemente o homem manifesta o seu caráter alienante $e$ fetichizado.

Esse contexto descreve o movimento do fetichismo impregnado nos diferentes espaços que, para Martins (2004), cada vez mais é perceptível na organização do mundo, isto é, a pressão que a ideologia dominante exerce sobre os indivíduos. Ao considerar tal afirmação, tomamos como reflexão os motivos pelos quais pensamos ou agimos como tal e, ao mesmo tempo, porque temos certas concepções a respeito de determinados conceitos, o que de fato, são imposições realizadas indiretamente de forma absoluta pela ideologia dominante.

\section{Concepção de infância}

Ao longo da história da infância, Stearns (2006) relata que é possível perceber os caminhos mais amplos que as famílias e sociedades percorreram no passado. A importância do conhecimento da infância no curso da história permite compreender como muitos de seus aspectos contemporâneos decorrem do passado, ao passo que proporciona uma perspectiva 
histórica ao presente.

Entender o conceito de infância apenas como uma fase biológica não é suficiente para romper com a naturalização tanto do desenvolvimento quanto da aprendizagem, comprometendo a relação do ser humano com o trabalho, descaracterizando o próprio processo de humanização. Encontramo-nos diante de uma realidade educacional e social em que a sociedade contemporânea fetichiza $a^{4}$ criança de tal forma que o papel do educador e dos pais, como formadores no processo de socialização, tem se descaracterizado. Por essa via, Saviani (2015), Martins (2004), Arce (2004), dentre outros, salientam a necessidade de se compreender que esses processos - tanto os de humanização e socialização, quanto os de fetichização - não são espontâneos e nem naturais, mas são reproduzidos dentro das relações de dominação e alienação na sociedade do capital.

Partindo desse princípio, Arce (2004), por sua vez, destaca que o conceito de infância é um termo socialmente produzido e se refere aos primeiros anos de vida e, por se tratar de uma elaboração social, apresenta múltiplas variáveis, sobretudo a complexidade dos processos históricos, econômicos e sociais. Consequentemente, o conceito de infância corresponde às particularidades e culturas geradas na fase do sujeito quando criança. Esse período é caracterizado por suas emoções e sentimentos, considerando que nem todos os adultos passaram por essa fase, visto que a história da infância de cada indivíduo depende de fatores relacionados à classe social, como fundamenta Kuhlmann Junior:

É preciso considerar a infância como uma condição da criança. O conjunto das experiências vividas por elas em diferentes lugares históricos, geográficos e sociais é muito mais do que uma representação dos adultos sobre esta fase da vida. É preciso reconhecer as representações de infância e considerar as crianças como produtoras da história (KUHLMANN JUNIOR, 1998a, p. 31).

Salientamos ainda que a infância tem um significado genérico, ou seja, um conceito que abrange vários termos, que se desenvolve a partir das transformações sociais. Nesses termos, a figura da criança na Idade Média era pouco destacada. Pode-se dizer que o

\footnotetext{
${ }^{4} \mathrm{O}$ termo fetichizar, originário do termo fetiche, é considerado como uma das características do processo que leva ao fetichismo, isto é, o fato de que as pessoas só veem aquilo que está imediatamente presente e não conseguem perceber o fato imediato à luz da totalidade social. O fetichismo é um fenômeno próprio do mundo da cotidianidade alienada, isto é, um desdobramento da alienação, é a naturalização de algo social (LIMA, 2010).
} 
sentimento de infância também não existia. As crianças eram inseridas no mundo dos adultos em uma idade precoce, fosse para aprendizado de um ofício quanto para condição de servos. A morte de crianças era considerada por todos como algo natural, e por assim pensar, a mortalidade infantil era cada vez mais elevada. Sobre isso, Heywood (2004) arrazoa que a infância durante a Idade Média não foi tão ignorada, mas era definida de forma imprecisa e por vezes desdenhada.

Nesse período, a discussão sobre a natureza da infância era pouco estimulada. Autores dessa época preferiam escrever sobre a idade adulta a dedicarem-se à infância. Uma investigação realizada por Heywood (2004) destaca que histórias e crônicas eram bastante vazias nessa área, chegando a mencionar um silêncio de mil anos em relação às crianças.

Desse modo, somente no final da Idade Média é que as representações artísticas que retratavam o termo infância foram ampliadas e diversificadas. Tais representações se aproximavam um pouco mais do sentimento moderno de infância. A burguesia, assim, começava a dar importância aos seus filhos, à sua educação e começou, então, a tratá-los de forma diferenciada, considerando-os como frágeis. Tais mudanças estavam diretamente relacionadas à expansão do comércio.

Sobre isso, Lucas (2005) ressalta que essas transformações não ocorreram nos diferentes grupos sociais, ao contrário, grande parte dessas mudanças incidiu com crianças da burguesia e nobreza; as demais - que não pertenciam a essas classes - ainda eram mantidas com pouco destaque. Suas vidas se limitavam na incorporação aos cruéis e assustadores ramos de produção, como mostra a autora mencionada. O sentimento de infância e o reconhecimento da criança como cidadã estavam em uma realidade distante para as crianças pobres e trabalhadoras.

Somente com o desenvolvimento da grande indústria, da tecnologia, da ciência e com a concretização do capital é que a criança se tornou dispensável enquanto mão de obra. Ainda segundo Lucas (2005), a criança precisava ser educada, necessitava frequentar uma escola para, então, ser preparada para o futuro. Percebe-se que foi também sob a orientação da organização capitalista que as políticas públicas para a infância começaram a ser pensadas na sociedade brasileira: "como novo personagem surgia a criança trabalhadora que passava a ser reconhecida como importante" (KRAMER, 2001, p. 60). Somente na década de 1930 que a 
infância se tornou um assunto de Estado no Brasil, com destaque para a criação do Departamento Nacional da Criança, em 1940, cujas iniciativas se restringiam à assistência e ao atendimento médico-higienista ${ }^{5}$, amparado pelas políticas eugenistas.

Esse novo olhar e o reconhecimento a respeito da criança se perpetuam até os dias atuais. A própria perspectiva marxiana parte do conceito da criança como sujeito histórico; seus pressupostos reconhecem que a criança, ao contrário de um ser passivo, é de fato um sujeito que constrói a sua história, transforma a realidade na qual está inserida e da mesma forma se transforma por esta realidade. Desse modo, pode-se dizer que o reconhecimento das crianças como cidadãs é uma conquista recente.

Deve-se ter a clareza que os conceitos criança e infância, de acordo com Carmo (2015), são resultados das relações culturais de uma determinada sociedade. Por isso não se deve considerar a criança como um ser apático, ao contrário, ela é um reflexo das práticas, do pensar, do agir dos adultos e do meio da sociedade em que vive.

A disparidade dos termos para se referir à criança e à infância vai além de simples conceitos, implica diferenças tanto dos objetivos e práticas pedagógicas quanto das modalidades de trabalho realizadas. Esses não são simplesmente conceitos teóricos, mas estão vinculados ao conjunto das relações sociais, sendo parte de uma totalidade maior e, consequentemente, não permanecem alheios às contradições de uma determinada sociedade.

Essa reprodução ideológica invade quase toda mentalidade cotidiana e os mais diferentes espaços, fazendo com que as relações históricas e sociais sejam tratadas como fenômenos naturais. A reprodução ideológica do fetichismo se realiza mediante muitas formas de naturalização dos fenômenos humanos, os quais são encarados como processos naturais. Essa naturalização, em larga escala, não ocorre só na aparência, mas mediante inúmeros subterfúgios, como a concepção fetichizada da infância. Logo, descaracteriza os conceitos de criança, trabalho, educação e, na verdade, destrona a relação do sentido dessas realidades, mais que isto, complexifica naturalmente a análise crítica, o pensamento, a reflexão.

\footnotetext{
${ }^{5}$ Esse movimento médico-higienista objetivava propostas assistenciais à infância para reduzir a mortalidade e se inseria em um projeto maior, o de saneamento, que visava atingir a civilidade e a modernidade. Teve influência na formação de uma concepção da criança como "pequeno reizinho". Para mais informações, consultar Kuhlmann Junior (1991) e Farias (2005).
} 
De acordo com Lima (2010), em diferentes momentos históricos e formas de produção, o fetichismo se articula às relações sociais e nelas se incorpora. Contudo, é preciso desvelar seu verdadeiro caráter alienador para que perca sua eficácia e seja desmascarado. É por esse motivo que a burguesia tanto se empenha em encobrir a natureza real dos acontecimentos históricos, bem como das coisas que fazem com que a aparência oculte a essência. É o que procuraremos discutir e refletir na descrição e interpretação dos dados.

\section{Resultados e discussão dos dados}

De acordo com os estudos realizados, é preciso compreender o conceito de infância historicamente construído, isto é, não é possível pensar uma concepção de infância única e homogênea, uma vez que há múltiplas particularidades que permeiam as diferentes crianças e infâncias. Essas diferenças são históricas, políticas, regionais, econômicas e sociais. Nesse sentido, de acordo com Oliveira (2005, p. 124-125), “[...] pretendemos fugir da imposição de um modelo de infância para orientar políticas sociais, o qual ignora as diferenças culturais e econômicas entre os indivíduos ou as trata sem percebê-las como desigualdades socialmente formuladas". Isso porque as complexidades culturais são essenciais na constituição do sujeito e para perspectivar alternativas e possibilidades de superação das contradições.

Diante disso, Arce (2004) destaca que a sociedade do capital traça uma visão idealizada da criança na qual a infância se torna uma proteção das mazelas produzidas pela sociedade. Esse processo é denominado de fetichização da infância, o qual atribui à criança uma condição indevida na sociedade; logo, o sentido de infância é descaracterizado. Ainda, de acordo com a autora mencionada, podemos afirmar que o fetichismo da infância é uma das manifestações claras do caráter alienante da sociedade capitalista contemporânea e este processo não permite que apareça o caráter histórico da criança, nem sua construção social, o que contribui de fato para a fetichização do sentido destas realidades. Mais que isso, o sentido da relação, educação, trabalho e criança é novamente reduzido à lógica do capital. Nesse caso, a autora considera ainda que o que parece ser uma valorização da criança e da infância constitui, meramente, um discurso ideológico que desvaloriza a educação - a escolar porque transforma o trabalho da escola somente em acompanhamento no processo de desenvolvimento da criança, propagando, desta forma, a alienação - e impõe a alienação aos indivíduos desde a 
mais tenra idade.

Desde o período em que surgiram os significados atribuídos à criança e infância, estes marcaram sensivelmente a sua constituição atual e futura. Exemplo disso são as inúmeras expressões e significados utilizados para se referir a tais conceitos, como se fossem um processo natural. Tais significados estão presentes nas indagações da pesquisa empírica a respeito das concepções de criança e infância nas quais percebe-se nos sujeitos entrevistados algumas respostas que identificam o mundo do senso comum, do empírico, das aparências, do engano, do pragmatismo. Desse modo, percebemos termos que fetichizam a infância, a criança, sua formação e educação, como destacado a seguir:

Criança é um sujeito de direito, a qual deve ser educado e protegido pela sociedade $\left(A^{6} 10\right.$, em 02/06/2015).

Criança é aquela que considero com suas particularidades, diferente dos adultos, um ser frágil que deve ser respeitado e protegido e que devemos considerar e oportunizar seus direitos e condições favoráveis ao seu mundo infantil (A12, em 02/06/2015).

Inocência (A13, em 02/06/2015).

Criança é um ser inocente que não sabe se defender, não sabe ir à luta, aos ataques (A16, em 02/06/2015).

Conforme as respostas anteriores, percebemos que os sujeitos idealizam o conceito de forma que, nesse processo, são descaracterizados enquanto futuros educadores, pois não reconhecem a criança como sujeito histórico, e não reconhecem, por sua vez, sua própria participação nesse processo. De forma que, temos como resultado, uma atuação docente que traça seu caminho desvinculado da constituição histórica.

Nota-se também um caráter alienante e ideológico descrito nos conceitos destacados pelos sujeitos, ou seja, os depoimentos mencionados estabelecem relações dos conceitos criança e infância ao mundo da imaginação e às suas devidas potencialidades e aprendizagens, o que de fato tornam conceitos fetichizados, trazendo como consequência a descaracterização do papel do educador e uma supervalorização da criança na sociedade.

Ser criança para mim é a fase em que somos puros, livres para brincar, pensar, onde sonhamos com muita imaginação e fantasias e somos pequenos (A33, em 02/06/2015).

\footnotetext{
${ }^{6}$ A caracterização dos sujeitos foi escolhida por letra (nesse caso, a letra A, que correspondente a aluno) e pela numeração em sequência. A data é correspondente ao desenvolvimento do questionário e entrevista.
} 
Por conseguinte, o fetichismo da infância reproduz um conceito ideológico, portanto, elabora um determinado imaginário sobre a criança, situando-a como ser naturalmente bom, portador de todas as virtudes desejáveis, tais como, inocência, confiança, liberdade, criatividade, fantasia e perfeição. Essas características revelam o aspecto histórico e social do significado da infância e influenciam decisivamente na "centralidade" que as crianças possuem na sociedade.

Certamente os sujeitos mencionados não desconhecem o conceito, apenas acreditam no que é impresso/divulgado pela mídia referente à criança e à infância. Sobre isso, Lima (2010) arrazoa que a forma fetiche é inverte a realidade. É aparencial, é a forma de manifestação em sua parte, em seu singular, usando a expressão de Marx "de cabeça pra baixo". Entretanto, ele afirma que não é o sujeito que está de cabeça para baixo, mas é a realidade que se encontra invertida.

Compreendemos que, no contexto atual, ou seja, na sociedade do capital, o trabalho se tornou um processo desumano e, desta forma, entende-se o fato de muitos serem contra o trabalho para a criança. Quem seria aquele que teria o domínio de retirar a criança desse contexto idealizado pela sociedade, que é a infância, para inserir no mercado de trabalho? Realmente, quando se observa o trabalho como algo isolado e fora da dimensão social, ele é considerado injusto, mas quando tratado como uma expressão da práxis, Marx nos faz refletir que esse processo é essencial para a formação da identidade do indivíduo, para que o mesmo pertença a determinado grupo social. Ao desenvolver essas questões desde a mais tenra idade, é possível permitir ao sujeito que se identifique, valorize e seja valorizado, e que se estabeleça relações com o mundo e com outros homens, de forma que o trabalho seja elaborado como um ato prazeroso.

Enquanto isso, quando analisamos a sociedade atual referenciada pelo processo de mercantilização, afirmamos a partir de tal perspectiva que a criança tem um papel fundamental neste contexto no que se refere a maior classe social para o mercado de consumidores. Como entender a proteção que a sociedade impõe sobre a criança em relação ao trabalho, sendo que ao mesmo tempo é cúmplice na inserção da criança como consumidora? Isso tudo não é o que contribui para a alienação do trabalho e o fetichismo da mercadoria? 
Em decorrência desse processo de mercantilização, o papel dos pais ou responsáveis e também dos educadores tem passado por uma desagregação social. Não mais conseguem controlar os desejos, vontades, necessidades e interesses das crianças por não conseguirem desempenhar com responsabilidade o papel de educar essa geração submetida ao consumismo infantil, o que torna o adulto, um escravo da infância como destaca Martins (2004).

Essa descaracterização social do papel dos pais se dá pelo fato das transformações ocorridas na sociedade contemporânea, as quais desfiguram de forma significante as concepções de paternidade, maternidade e infância. Nesse sentido, o principal motivo que se destaca é justamente o trabalho, que, no modo capitalista de produção, transforma essas relações, o ser humano e a própria infância em mercadoria.

Conforme destaca Lima (2005), o tempo das famílias para se dedicarem aos filhos tem sido roubado por esse modo capitalista de produção, interpretado pela maneira como somos condicionados a pensar e viver no mundo globalizado. A única maneira encontrada de compensar qualquer falta é pelo "afeto mercantilizado", gerado pelas campanhas e propagandas que realmente investem de diversas formas nesse público-alvo, que busca contrabalançar a "falta de tempo" ou tempo escasso e/ou minimizado com presentes e produtos.

Mascarenhas (2012) afirma que, mesmo não participando diretamente do contexto do trabalho, a infância encontra-se fetichizada, já que o processo de alienação do trabalho e o fetichismo da mercadoria alcançam todos os espaços da vida social, e, desta forma, há um processo desumano de mercantilização dos componentes da vida social em que a infância, por sua vez, também participa dele. Ao aceitarmos isso, contribuímos para um estado de desagregação social.

Nessa linha de pensamento, surge a necessidade do pensamento científico para apreender o concreto, a essência, pois o imediato não está dado na sua aparência. Faz-se necessário romper com o nível de representação, retirando o que ele encobre, visto que o compromisso é de revelar a realidade e a verdade. É preciso ainda mencionar que essa aparência, além de falsa, é ilusória, mas, sobretudo, é real. Nesse sentido, Marx (1996) aponta que não é uma coisa ou outra, mas uma coisa e outra. É real enquanto existência concreta, 
mas é ilusória na medida em que não expressa as relações em que de fato são constituídas.

Ainda sobre os resultados encontrados a partir das entrevistas, os depoimentos revelaram também que muitos entrevistados concebem a criança como ser criativo, feliz, cheio de carisma, sujeitos totalmente dependentes dos adultos; este fato parece determinante para pensar a relação trabalho, educação e infância. Conforme afirmam as/os entrevistadas/os:

Criatividade, imaginação, felicidade, inocência, carisma, atenção etc. (A43, em 02/06/2015).

Criança, ah criança, é um ser maravilhoso, algo que merece ser cuidado com toda atenção e carinho, da melhor forma possível, mas infelizmente não acontece sempre (A51, em 02/06/2015).

Criança é ter infância (A52, em 02/06/2015)

Diante de tais respostas, percebemos que é comum encontrarmos educadores com o viés de natureza infantil descontextualizada do mundo, em que a criança é considerada como um ser abstrato. Dessa forma, percebe-se uma naturalização das concepções de criança, visto que os futuros educadores expressam de maneira alienante a busca pela preservação e proteção à criança.

Cabe aqui mencionar o quanto esse processo de fetichismo invade os vários campos e aspectos históricos da sociedade. É possível notar esse fato por meio da postura dos sujeitos. Ao serem indagados sobre ser a favor ou contra o trabalho para criança, os resultados mostraram que os indivíduos se encontravam divididos, mas a maioria destacou claramente que era contra o trabalho para criança, conforme demonstram as falas:

\footnotetext{
O trabalho não é para criança, criança precisa brincar, estudar, ter liberdade para viver sua infância (A14, em 02/06/2015).

Contra, o trabalho infantil é um ato de violência, que rouba a infância e acelera uma fase em que se constrói valores éticos e morais (A29, em 02/06/2015).

Contra, se a criança é poupada de brincar na infância isso pode trazer traumas irreversíveis (A44, em 02/06/2015).
}

Dentre outros sujeitos que se mostraram contrários ao trabalho para criança, sempre relacionam o fato de essa etapa da vida ser constituída apenas pelo brincar, pelo lúdico, não reconhecem que o ser criança é também ser histórico e que se constitui a partir da transformação da realidade na qual está inserida e também se transforma por esta realidade. 
Da mesma forma, alguns sujeitos foram contra o trabalho para a criança por compreenderem que o seu lugar não era nesse contexto, como destacado a seguir:

Contra, porque a criança deve vivenciar uma infância em que possa brincar, estudar e relacionar o trabalho como complemento futuro e não privar seu desenvolvimento infantil (A26, em 02/06/2015).

Sou contra que a criança trabalhe, devem estar na escola estudando e não trabalhando (A36, em 02/06/2015).

Lugar de criança é na escola (A42, em 02/06/2015).

Considerando o trabalho como uma atividade fundante da sociabilidade e a educação originária deste processo, ou seja, a educação é instrumento essencial da socialização, não há como pensar tais conceitos isolados. De acordo com as análises, é possível compreender que os sujeitos destacados desconheciam a concepção de trabalho como atividade produtora que é ação transformadora consciente -, desconsideram a sua essência e de como é vital para o homem, conforme descrito nas concepções marxianas. Conceberam o trabalho como tortura, no âmbito do processo de alienação. Assim, tais sujeitos destacaram que eram contra o trabalho para criança, alegando que lugar de criança era na escola.

Entendemos que esse tema nos exige atitudes sensíveis e corajosas, uma vez que ao analisarmos essa problemática, faz-se necessário olhar para o passado e compreendermos a configuração que o trabalho adquiriu nessa forma societal e percebermos, conforme já mencionado, que não é o indivíduo que se engana, mas a realidade que se encontra invertida. Percebemos que os sujeitos responderam baseados no senso comum ou no que a mídia propaga envoltos em uma rede tecida de invisibilidade sobre a concepção de trabalho. Por isso a importância da formação teórica sólida do professor, que promova o questionamento da realidade fetichizada e alienada que se impõe aos indivíduos, uma vez que o conhecimento resulta do trabalho humano no processo histórico de transformação do mundo e da sociedade por meio da reflexão sobre esse processo. No entanto, cabe aqui uma indagação: estudar não é trabalho?

O trabalho contextualizado por Marx é considerado como princípio educativo. Para tanto, recorremos ainda a Gramsci (1979) que congrega o âmbito emancipatório das ideias pedagógicas contra-hegemônicas. Tal concepção estabelece e articula uma ligação entre o sentido do trabalho e o sentido da educação. Entretanto, é preciso afirmar, que não queremos e nem é devido entender trabalho como sinônimo de emprego, ao contrário, é necessário 
enfatizar o trabalho como expressão da práxis - ação transformadora (MARX, 1996).

Por essa via, o trabalho no sentido ontológico, ou seja, aquele trabalho entendido como pertencente ao homem em si, ao seu ser e ao mesmo tempo articulado à natureza é uma condição existencial do homem, a necessidade natural de mediação do metabolismo que afirmamos. Ao pensar o sentido da criança, da educação e do trabalho podemos também afirmar que, aqui, percebemos verdadeiramente a relação destas realidades investigadas: desde os primeiros anos de escolaridade, é preciso desenvolver atitudes e atividades de investigação, reflexão crítica e participação ativa dos educandos, desde a mais tenra idade, na articulação dos conteúdos7, possibilitando passar do senso comum particular, para os conceitos científicos que permitirão a compreensão da realidade em suas diferentes dimensões. Vale ressaltar que, de acordo com a investigação de Gramsci (1979), sem dúvida o estudo é um trabalho, e trabalho árduo.

Deve-se convencer a muita gente que estudo é também um trabalho, e muito fatigante, com um tirocínio particular próprio, não só muscular nervoso, mas intelectual: é um processo de adaptação, é um hábito adquirido com esforço, aborrecimento e mesmo sofrimento (GRAMSCI, 1979, p. 138-139).

Observando essa concepção de educação gramsciana, percebemos que desde os primeiros anos de escolaridade os educandos devem entender o ensino como trabalho sistematizado, disciplinado, relacionado a atividades produtoras e criadoras.

\section{Referências}

ARCE, Alessandra. Pedagogia da infância ou fetichismo da infância? In: DUARTE, Newton (org.). Crítica ao fetichismo da individualidade. Campinas: Autores Associados, 2004. p. 154-168

ARCE, Alessandra. O referencial curricular para a educação infantil e o espontaneísmo: recolocando o ensino como eixo norteador do trabalho pedagógico com crianças de 4 a 6 anos. In: MARTINS, Lígia M.; ARCE, Alessandra (org.). Quem tem medo de ensinar na educação infantil? Em defesa do ato de ensinar. Campinas: Alínea, 2007. p. 13-36.

BRASIL. Lei n. 8.069, de 13 de julho de 1990. Estatuto da Criança e do Adolescente. 9. ed. Brasília: Câmara dos Deputados, Edições Câmara, 2012. Disponível em:

\footnotetext{
7 Segundo Martins (2009, p. 94), “[...] como conteúdos de ensino os conhecimentos mais elaborados e representativos das máximas conquistas dos homens, ou seja, componentes do acervo científico, tecnológico, ético, estético etc., convertidos em saberes escolares. Advogamos o princípio segundo o qual a escola, independentemente da faixa etária que atenda, cumpra a função de transmitir conhecimentos, isto é, de ensinar como lócus privilegiado de socialização para além das esferas cotidianas e dos limites inerentes à cultura de senso comum".
} 
http://www.crianca.mppr.mp.br/arquivos/File/publi/camara/estatuto_crianca_adolescente_9ed .pdf. Acesso em: 12 fev. 2019.

CARMO, Aline Cristine Ferreira Braga do. A infância permeada pelo consumismo e os desafios ao trabalho docente. 2015. 195 f. Dissertação (Mestrado em Educação) Universidade Federal de Goiás - Regional Jataí, Jataí, 2015.

FARIAS, Mabel. Infância e educação no Brasil nascente. In: VASCONCELOS, Vera Maria Ramos de (org.). Educação da infância: história e política. Rio de Janeiro: DP\&A, 2005. p. $33-49$.

FRIGOTTO, Gaudêncio. O fim da sociedade do trabalho e a não centralidade do trabalho na vida humana. In: VASCONCELOS, Vera Maria Ramos de (org.). Educação e a crise do capitalismo real. São Paulo, Cortez, 2000. p. 91-134.

GIL, Antônio Carlos. Como elaborar projetos de pesquisa. São Paulo: Atlas, 2010.

GRAMSCI, Antonio. Os intelectuais e a organização da cultura. Rio de Janeiro: Civilização Brasileira, 1979.

HEYWOOD, Colin. As transformações nas concepções de infância. In: HEYWOOD, Colin (org.). Uma história da infância. Porto Alegre: Artmed, 2004. p. 23-59.

KUHLMANN JUNIOR, Moysés. Instituições pré-escolares assistencialistas no Brasil (18991922). Cadernos de Pesquisa, São Paulo, n. 78, p. 17-26, ago. 1991.

KUHLMANN JUNIOR, Moysés. Infância e educação infantil: uma abordagem histórica. Porto Alegre: Mediação, 1998a.

KUHLMANN JUNIOR, Moysés. A educação assistencialista. In: KUHLMANN JUNIOR, Moysés (org.). Infância e educação infantil: uma abordagem histórica. Porto Alegre: Mediação, 1998b. p. 181-196.

KUHLMANN JUNIOR, Moysés. As exposições internacionais e a difusão das creches e jardins de infância. In: KUHLMANN JUNIOR, Moysés (org.). Infância e educação infantil: uma abordagem histórica. Porto Alegre: Mediação, 1998c. p. 71-80.

KRAMER, Sonia A política do pré-escolar no Brasil: a arte do disfarce. 6. ed. São Paulo: Cortez, 2001.

LIMA, Laís Leni O. Políticas públicas educacionais para a educação infantil de Jataí: da proposição à materialização. 2005. 153 f. Dissertação (Mestrado em Educação) - Faculdade de Educação, Universidade Federal de Goiás, Goiânia, 2005.

LIMA, Laís Leni O. As muitas faces do trabalho que se realiza na educação infantil. 2010. 262 f. Tese (Doutorado em Educação) - Faculdade de Educação, Universidade Federal de Goiás, Goiânia, 2010.

LUCAS, Maria Angélica Olivo Francisco. Educação infantil: algumas reflexões sobre seus fundamentos teóricos e metodológicos. Revista HISTEDBR On-line, Campinas, n. 17, p. 79-90, mar. 2005. Disponível em:

http://www.histedbr.fe.unicamp.br/revista/revis/revis17/art08_17.pdf. Acesso em: 23 nov. 2015.

MANACORDA, Mário Alighiero. Marx e a pedagogia moderna. 3. ed. São Paulo: Cortez, 2007.

Argumentos Pró-Educação, Pouso Alegre, v. 4, n. 12, p. 1118-1138, set. -dez., 2019

ISSN: 2448-2803 http://dx.doi.org/10.24280/ape.v4i12.519 
MARTINS, Lígia Márcia. Da formação humana em Marx à crítica da pedagogia das competências. In: DUARTE, Newton (org.). Crítica ao fetichismo da individualidade. São Paulo: Autores Associados, 2004. p. 53-74.

MARTINS, Lígia Márcia. O ensino e o desenvolvimento da criança de zero a três anos. In: ARCE, Alessandra; MARTINS, Lígia Márcia (org.). Ensinando aos pequenos de zero a três anos. Campinas: Editora Alínea, 2009. p. 93-121.

MARX, Karl. Manuscritos econômico-filosóficos. Textos filosóficos. São Paulo: Editora Nova Cultural Ltda, 1996.

MARX, Karl. O capital: crítica da economia política. São Paulo: Nova Cultural Ltda., 2002.

MASCARENHAS, Ângela Cristina Belém. Objetividade e subjetividade do trabalho. In: MASCARENHAS, Ângela Cristina Belém (org.). O trabalho e a identidade política da classe trabalhadora. Goiânia: Alternativa, 2002. p. 49-75.

MASCARENHAS, Ângela Cristina Belém. Relação educação e trabalho na infância. In: MASCARENHAS, Ângela Cristina Belém; ZANOLLA, Silvia Rosa Silva (org.). Educação, cultura e infância. Campinas, São Paulo: Alínea, 2012. p. 51-60.

MÉSZÁROS, István. A educação para além do capital. São Paulo: Boitempo, 2005.

OLIVEIRA, Zilma Ramos de. Educação infantil: fundamentos e métodos. São Paulo: Cortez, 2005.

SAVIANI, Dermeval. Pedagogia histórico-crítica: primeiras aproximações. Campinas: Autores Associados, 2003.

SAVIANI, Dermeval. O trabalho como princípio educativo frente às novas tecnologias. 2015. Disponível em:

http://www.ufpr.cleveron.com.br/arquivos/EP_104/dermeval_saviani.pdf. Acesso em: 30 nov. 2017.

STEARNS, Peter N. Introdução: a infância na história mundial. In: STEARNS, Peter N. A infância. São Paulo: Contexto, 2006. p. 11-20.

TRIVIÑOS, Augusto N. S. Introdução à pesquisa em ciências sociais: a pesquisa qualitativa em educação. São Paulo: Atlas, 2015. 